\title{
Reforming Regulatory Institutions: Enlarging the Space of Reasons
}

\author{
Henry Kelly ${ }^{1}$
}

\begin{abstract}
The most recent phase of global capitalism has been characterised by neoliberal arguments which have supported the deregulation of large sectors of world financial markets. This phenomenon has led to so-called financialization with capital attempting to separate itself from the material base of the economy. The instability of this form of economic activity in addition to the highly attractive short-term returns the financial sector has offered has been the main driver of the current global financial crisis.

This article will seek to examine the manners in which global regulatory frameworks can be reformed to ameliorate the current crisis and create an institutional architecture that will be robust to future shocks. It will be argued that reform needs to proceed in two directions depth and breadth. During the neoliberal phase of economic development, the public discourse on economic policy has centred on arguments based solely upon economic value, it will be suggested that a reformed framework needs to take into account and admit into the space of public reasons, ethical, aesthetic and civic arguments. This is due to the highly volatile nature of economic value and the necessity to acknowledge that in addition to being producers and consumers economic agents are also people.

In a similar vein following the work of Karl-Otto Apel on the public sphere, international regulatory institutions should take into consideration and be accountable to all those effected by their policies and actions. Given the increasingly integrated nature of the European and World economies agencies need to be rendered democratic
\end{abstract}

Keywords:

Regulation, Financial Markets, Financialization, Public Reason, Ethics

JEL Classification:

A13,G01,G18,Z18

\footnotetext{
1 Trinity College Dublin. Email: kellyhe@tcd.ie
} 


\section{Introduction}

Following the onset of the Global Financial Crisis a consensus has emerged which maintains it is necessary to reform regulatory structures and introduce tighter regulations on the operation of financial markets. While such a development is welcome there is a danger that any reforms will fail to deal with the crucial issues that a global regulatory framework must address. The following contribution will argue that any attempt to reform agencies and institutional structures must address the normative questions which underpin any economic system. The analysis will begin by briefly contextualising the current financial crisis and policy discussion, in such a way as to highlight the neglect of a normative foundation to regulatory policy. The consequence of this development will then be de-lineated, blindness towards acknowledging the influence of value judgements upon policy outcomes has led to a focus on the unidimensional goal of efficiency. The following sections will introduce two theoretical arguments that justify an enlargement of the space of reasons both within reformed institutions but primarily in discussions about reform. The work of Axel Honneth on recognition ethics can aid an analysis of the restriction of the policy space to arguments that follow a hegemonic economically focused logic, whilst arguing for a pluralisation of recognition to allow a broader range of goals to be recognised. In addition the work of Karl-Otto Apel on the structure of communication communities can provide a normative foundation for the inclusion of a wider range of actors in discussions on regulatory policy.

\section{The Background to the Crisis and Regulatory Policy}

The most recent phase of global capitalism has been characterised by neoliberal arguments which have supported the de-regulation of large sectors of global financial markets. A number of factors led to the rise of neoliberal ideas in the global policy space, above all a suspicion of state intervention in the economy whilst ideological arguments which present the market as a value-free arena of freedom have contributed to the maintenance of a neoliberal hegemony at least until the recent Global Financial Crisis.

A consequence of de-regulatory policy and the increased freedom of capital to circulate along with financial innovations has been so-called financialization which can be seen as the separation of financial returns from labour and the material base of the economy. Such a form of economic activity is highly unstable, and has been viewed from a Keynesian-Minskian tradition as leading to an inevitable crisis. From these perspectives a crisis will arise when overly optimistic expectations re-adjust to the fundamentals of the economy. Such crises along with the initial process of financialization are undesirable as in addition to the negative welfare effects of rapid economic reversals they bring about a lack of confidence in the financial sector which renders it difficult for it to fulfil its role. 
Given the failure of the de-regulatory experiment and the enduring nature of the Global Financial Crisis there is an imperative to examine ways of reforming the existing national, regional and global financial architecture and regulatory frameworks. This can't be achieved simply by returning to a state focused model of regulation that existed in the Bretton Woods era. There has been a shift in the nature and volume of international economic activity of both tangibles and intangibles that renders such a framework unworkable. In addition states are a lot less powerful and influential than they were in the immediate post-war period and would struggle to enforce such a rigid system. Above all the primary reason not to return to such a system which is based on predominantly state centred regulation is that the main dangers any reformed regulatory system faces is similar to that which brought about neo-liberal critique in the 1970s. Richard Peet and Greta Krippner both demonstrate the political nature of the move to a financially centred economy. (Krippner 2011; Peet 2011) More abstractly the move towards a finance led regime may be seen to accompany a transition to a World increasingly centred on the rapid transmission of images. A material basis or at least a material condition of the possibility for the current extent of financial transactions is the rapid and global spread of internet communications technologies.

Although financialization has been viewed by some (Teixiera and Rotta 2012) as an attempt by capital to render itself autonomous from labour and material production. This is accompanied by an increasing focus upon the immaterial economy, an economic reality governed by the creation and manipulation of images rather than the production of tangible goods and services. Autonomist writers have contextualised this phenomenon as a response by capital to the increasing mobilization and organisation of workers in the initial post-war period. Capitalists started to dismantle the spaces that allowed workers to become aware of their own subjectivity and replace them with an individualised liquid economy. Although they have been somewhat successful in this goal the shift to immaterial production is accompanied by heightened instability. The exchange value of material goods has a tangible base in the cost of the raw inputs and the labour time required to produce them. In the case of immaterial goods and services, the most extreme example of which is finance and financial derivatives there is no tangible basis for price formation. This leads to highly volatile economic situations as the price of goods and services comes to depend entirely upon expectations. Financial assets ultimately depend upon tangibles which in turn depend on labour both for production and consumption ${ }^{2}$.

Finance's rise to hegemony is clearly linked to an attempt by capital to extricate itself from being entwined with labour. This is clearly contradictory as the crisis has shown, yet this hasn't eliminated the fiction, as Haiven writes, "crises are the result of the necessary failure of capital's self-representation in price, its chronic inability to

\footnotetext{
${ }^{2}$ In the case of real estate, the value of the existing house stock only depends on people being able to afford it, or at least have a credit line.
} 
accurately assign value to social goods and cooperation"( Haiven 2011,p.112). The profits made by financial institutions even following the Global Financial Crisis are much larger than those made in industry, agriculture or other services. After the Crisis finance has come to depend to being bailed out through the tax system, the intervention of Government as an intermediary has allowed the Crisis and separation from productive work to be overcome. Governments instead transfer the fruits of workers' labours to the financial sector in the form of state aid. This at least formally is dependent upon the democratic consent of the governed. They must then view finance as of such importance to the economy that it is worth sacrificing all of production for its wellbeing. This social superiority which the financial sector has been be assigned must according to Thenevot and Boltanski be justified by a perceived special contribution to the social good. As the effects of the global financial crisis and recession accelerate and worsen this becomes increasingly hard to justify. The financial sector rather than making an especially valuable contribution to society and the economy is through bank bailouts ,and the austerity packages necessary to allow them to occur, draining the material well-being from the economy.

\section{The Necessity of a Normative Foundation to Regulation}

There is a risk of state ${ }^{3}$ intervention being captured by certain interest groups, leading to powerful lobbies being favoured by the regulatory framework, new-entrants being penalised and the consumers of goods and services losing out. The key point to note is that even so-called free markets, with little or no state interventions can and normally do experience a similar process with the rise of hegemonic monopolies that are able to manipulate the market and public policy in their favour. The argument that free market and de-regulation removes value judgements from the economic sphere is itself stems from meta-theoretical doctrine. The Werturteilsstreit between Max Weber and Gustav Schmoller ended in the victory of Weber's position which maintained the necessity of and existence of a positive value free (social) science. This position has been heavily influential in all social sciences, but reached a higher level of dominance in economics, with its inclination for quantitative methods, it maintained that there needed to be a strong division between scientific facts and normative judgements about these facts. The tradition associated with Schmoller on the other hand held that the manner in which we frame, interpret and assess the object of our study can't but be influenced if not driven by normative judgements. Given this insight it is better to explicitly acknowledge these values rather than to attempt to conceal them.

The key factor that any reformed regulatory infrastructure needs to consider is its ethical and normative basis. Following Schmoller it will be maintained that in the same way free markets and their analysis is not free from normative influence, regulatory

\footnotetext{
${ }^{3}$ I am using State loosely; this applies equally to inter-state bodies on a regional or global level.
} 
architecture can't be based solely upon efficiency considerations. For this reason it will be argued that any reform of the international financial architecture needs to proceed in two directions, breadth and depth. Recent literature on reforming the institutions of global financial governance both in the aftermath of the Russian and Asian financial crises of 1998-9 and the Global Financial Crisis which began in 2008 have primarily focused upon the efficiency and effectiveness of such structures. While it is certainly true that the international financial architecture is over-stretched performing functions that differ greatly from those it was designed to perform and there is a necessity to reduce regulation and control on financial trading to increase the effectiveness and the ability of the financial system to function. There is a deeper necessity to provide a strong normative basis to any institutional apparatus if true reform and enhanced performance is going to occur and the problems of special interests, regulatory capture and hegemony are going to be overcome in a democratic fashion.

\section{Enlarging the Space of Reasons-Depth-Recognition and Plurality}

In order to increase the breadth of reform the discursive space within both regulation and discussions about regulation must be broadened to allow for the admission of wider plurality of interests. During the neoliberal phase of economic development, the public discourse on economic policy has been centred upon arguments based solely upon economic value, with price seen as been equated with value. It will be suggested that a reformed framework needs to take into account and admit into its space of public reasons, ethical, aesthetic and civic arguments. This section will draw upon insights from the work of Axel Honneth on recognition ethics, in addition to the writings of Thevenot and Boltanski on Orders of Standing.

In a similar vein following the work of Karl-Otto Apel on the public sphere international regulatory institutions should take into consideration and be accountable to all those effected by their policies and their actions. Given the increasingly integrated nature of the European and World economies agencies need to be rendered democratic. Apel proposes a Kantian based conception which focuses on the Right procedures to structure decision making. At the present time most discussions on regulation and the structure of international finance take a limited set of given actors to be involved, mainly banks, states and transnational organisations. Little thought is given to other micro-level actors affected by policies.

Axel Honneth's work on struggles for recognition can provide an insight into the mechanisms which have led to only reasons which make use of certain arguments have been able to capture discursive space. In "The Struggle for Recognition" Honneth reconstructs Hegel's Phenomenology of the Spirit and with it a tripartite division of ethical life. Subjects are posited as only obtaining self-confidence, self-respect and selfesteem through an inter-subjective phenomenology of the self (Honneth 1996, p.94). In 
the sphere of the family subjects are recognised and loved in a manner which fosters self-confidence, in the sphere of the State subjects are recognised as autonomous beings in a manner which fosters self-respect and in the societal sphere what is particular about subjects, their individual contributions to the abstractly defined goals of society are recognised allowing them to attain self-confidence(Honneth 1996, p.121).

It is the societal sphere and the form of recognition which takes place within it that is of interest for the current analysis. Subjects attain self-confidence when society recognises the value of their individual contribution to the collective goals which society pursues. It is having their contribution valued and recognised by others that allows subject to be confident about their own value for society.

Given the abstract nature of societal goals in the modern era, an interpretative framework is required to mediate between the concrete contributions and talents of individuals and broad societal goals (Honneth 1996, p.129). For Honneth a struggle for recognition is the process by which groups and individuals that believe they are misrecognised attempt to convince broader society of the value of their contribution by symbolic and material means. Honneth maintains that all economic remuneration is a consequence of the ability of groups within a given profession to capture the semantic framework and grammars of recognition in such a way that their contribution is viewed as more socially valuable and is accordingly awarded a higher amount of material remuneration (Honneth 2001, p.52-54).

The nature of recognition relations in the societal sphere and the character of the economic distribution which flows from it have become hegemonically structured. Honneth analysis argues for a pluralisation of ideas of the good and what is taken to be valuable that would allow a broader range of lifestyles to be recognised and therefore remunerated.

Honneth's work can be supplemented by that of Thevenot and Boltanski on Orders of Standing. They argue that there are different orders within which different attributes are acknowledged and social esteem obtained. The problem is when one order, at present that centred on economic value and success in the commercial and financial sectors is able to vertically impose itself on the others (Boltanski \& Thevenot 1991). Adam Smith work on Rhetoric and Belles letters follows in a similar vein. In this relatively neglected text Smith explains his famous comment about the eternal desire of man to truck and barter. This desire is a consequence of man's search for social esteem by his peers, for Smith the activity that is most highly esteemed is rhetoric ability. The ability to convince one's interlocutors, this is achieved in the most quantifiable and materially visible manner in the market place (Kalyvas and Katznelson 2001). The ability to convince others to one's advantage is highly esteemed, or returning to Honneth to manipulate the semantic and semiotic bridge in such a way as to demonstrate favourably one's contribution to the goals of society ${ }^{4}$.

\footnotetext{
${ }^{4}$ It isn't the contribution one makes through commerce that is esteemed by Smith, but at a meta-level, the ability to convince others of the value of that contribution.
} 
Markets are not simply arenas for the instrumental quest by competitive and strategic individuals to secure their material preferences, they are also a central mechanism for social integration derived not from strategic self-interest but rather the inexorable struggle by human agents for moral approbation and social recognition (Kalyvas \&Katznelson 2001 pp.533-534). With sympathy moral judgments are derived from a person's ability to identify with someone else's situation and feelings through the faculty of imagination by entering and the experiencing the position of the other. We sympathise because we wish to be praised,esteemed even loved. Rhetoric emerges as a ligature connecting the core themes of recognition and exchange through a theory of speech. Smith distinguished between four forms of discourse; poetic, narrative, didactic and oratorical/rhetorical(Kalyvas \& Katznelson 2001p.562). The primary function of oratorical speech is to persuade an audience about a controversial issue through the communication of sentiments and emotions. Oratory is not directed towards achieving truth, but to change beliefs and opinions, to transforms perceptions and to gain the assent of one's interlocutors.

For Smith the faculty of speech is grounded in a deeper more essential trait, the drive to be recognised by others. In ancient democratic politics there was an underlying struggle for recognition invested in an unique form of political competition among striving individuals each seeking to win the appropriation of their fellow citizens by persuading them to support their proposed public policies (Kalyvas \&Katznelson 2001 pp.563-564). An application of Honneth's analysis of recognition to regulatory structures can serve to aid the development of the study of both. Including a more concrete policy space where the consequences of the structuring of recognition relations becomes manifest can add a missing step to Honneth's framework. While considering the structures of regulatory and financial agencies through the lens of recognition ethics can aid the development of a robust normative foundation to such organisations. The logic and grammar which operate within regulatory institutions needs to be expanded to allow for a range of distinct orders of standing and subjects within respective orders of standing to be recognised as contributing to society. Neoliberalism but also institutions during the Bretton Woods era have tended to focus solely upon economic value. That is value seen through the interpretive framework of those in dominant positions. Under neoliberalism this has led to a regulatory system that favours short-term profit over all other goals. Given that financialization involves a separation of activities in the financial sector from concrete productive activities this phenomenon has had negative consequences for society and has led to high volatility. During the Keynesian Bretton Woods period institutions were also orientated towards economic value. Institutions should expand their range of goals above that of economic efficiency to allow civic, ethical and aesthetic reasons to play a role in the both the determination of regulatory policy and by structuring the regulatory apparatus to allow the fostering of such values. 


\section{Enlarging the Space of Reasons-Breadth- Legitimacy, Procedure and Inclusion}

It may be argued that one of the reasons institutional structures and the recognition relations that occur within them are skewed towards economic value in the form of short term profit, is that the participants and policy makers within these agencies are those that have captured the semantic bridge and are able to impose their normative conception. This brings the discussion to the second direction reform must proceed in, that of breadth. While only certain types of reason are admitted into the arena of regulatory discussion as legitimate a potentially greater fault is that only a very limited set of reasoners are admitted. In the contemporary globalised economy the character of regulatory policy and the shape and nature of the international financial architecture affects every person on the planet. Yet the policy of these agencies is determined solely by representatives of the most significant states and often even within that subset policy is determined by a smaller transnational set of actors. In addition to a crisis of effectiveness regulation also faces a crisis of legitimacy. Even during discussions that have taken place with regards national and regional reforms following the global financial crisis the actors participating and been considered as significant for policy have been a very limited elite, often concentrated within the financial sector. Regulation policy faces a crisis of legitimacy on two fronts, firstly at a global governance level, but also at a sub-global level as even if a larger range of countries was able to attain a significant role in global policy discussions this would still lack legitimacy if participation was limited to the global financial elite.

The work of Karl-Otto Apel may provide an appropriate normative foundation that would allow for a broader range of participants into discussions on economic structures. Current debates on regulatory reform pay little attention to either the procedural structures to be implemented within agencies nor perhaps more significantly that there is a failure to reflexively consider the composition of those deciding on which reforms to implement. Apel argues that in an increasingly globalised world the creation of a universally acceptable procedural framework is necessary (Apel 2000). This framework for deciding on policies which have a global impact must be free of any specific cultural influences or substantive conceptions of the Good. Departing from the perspective of pragmatist language theory, the guiding principle is that subjects avoid utterances which are performative contradictions. All discussion should seek to include and at the very least take into consideration the arguments and interests of all those who will be affected by the decision. Seeking such a normative foundation to regulatory procedure will prevent regulatory capture by certain interest groups while also allowing a broader civic ethic to assert an influence on policy.

It is through the development of a strong normative basis orientated towards plurality and legitimacy that regulation can be rendered effective for the tasks and duties it must perform in the current globalised world. It is necessary to expand the range of reasons 
as well as the range of people whose reasons are considered. This process will prevent both a focus upon a single short-term goal such as financial profit and the hegemony of any single social group.

\section{Concluding remarks}

The economy and society are composed of numerous communities of value each with their own grammars of recognition, meaning and value. Communities of value can be understood as groups of people that share enough among themselves to be able to exchange ideas, opinions, thought on basic principles that involve values and valuation with minimal potential for misunderstanding. Within each of these communities - be they classical music, the visual arts or tax accountancy - ideas and concepts of the good and the value circulate in various fashions. The value being assessed may be symbolic in the form of token prizes and peer recognition or material as with financial remuneration. The key principle remains the meaning and goals which are produced by peers within that community, rather than the external and anonymous allocation of market value. Reformed financial regulatory institutions need to be aware of this fact and permit a broad variety of distinct reasons and actors to be admitted into their discursive space.

There is a requirement for a new mode of economic analysis that recognises the legion objectives of actors and the plurality of concepts of the good that exist in society. It is only through learning the diverse languages and production of meanings that we can begin to understand the diversity of human economic activity and the true breadth of currencies and values which circulate. If we fail to do this we risk being left with an economics that is unable to prevent the material, culture and ecological destruction of our world. The reform of regulatory institutions provides an excellent opportunity to begin achieving this.

\section{References}

Apel, K-0, 2000. "Globalization and the Need for Universal Ethics", European Journal of Social Theory, Vol.3 No.2, pp.137-155.

Boltanski, L., Thévenot, L., 1991. “On Justification”, Princeton University Press, Woodstock, Oxfordshire.

Haiven, M, 2010. "The Financial Crisis as a Crisis of Imagination”, Cultural Logic,pp.1-23.

Haiven, M., 2011. “Finance as Capital's Imagination”, Social Text, Vol.29 No.3,pp.93-124.

Honneth, A 1996, The Struggle for Recognition: The Moral Grammar of Social Conflicts, The MIT Press, Cambridge, Massachusetts.

Honneth, A., 2001. "Recognition or Redistribution? Changing Perspectives on the Moral Order of Society", Theory, Culture and Society, Vol.18 No.2-3, pp.43-55. 
Kalyvas, A., Katznelsen, I., 2001. "The Rhetoric of the Market: Adam Smith on Recognition, Speech and Exchange", Review of Politics, Vol.63 No.3, pp.549-579.

Krippner, G. R., 2011. "Capitalising on Crisis: The Political Origins of the Rise of Finance", London: Harvard University Press.

Peet, R., 2011. "Inequality, Crisis and Austerity in Finance Capitalism", Cambridge Journal of Regions, Economy and Society Vol.4,pp.383-399.

Teixeira, R.A, Rotta, T. N., 2012. "Valueless Knowledge-Commodities and Financialization: Productive and Financial Dimensions of Capital Autonomization", Review of Radical Political Economics,Vol. 44No.4, pp.448-467. 